\title{
Factors Affecting Outcomes in Patients With Stage III \& IV Squamous Cell Carcinoma of Oropharynx: The Importance of p16 Status, BMI, and Race
}

\author{
Mary R. Nittala ${ }^{1}$, Madhava R. Kanakamedala ${ }^{2}$, Eswar Mundra ${ }^{1}$, Toms Vengaloor Thomas ${ }^{1}$, Eldrin Bhanat \\ ${ }^{3}$, William C. Woods III ${ }^{1}$, Srinivasan Vijayakumar ${ }^{1}$ \\ 1. Radiation Oncology, University of Mississippi Medical Center, Jackson, USA 2. Radiation Oncology, Texas Oncology, \\ Amarillo, USA 3. Orthopaedic Surgery, University of Mississippi Medical Center, Jackson, USA
}

Corresponding author: Mary R. Nittala, mnittala@umc.edu

\section{Abstract \\ Objective}

To identify racial disparities in survival outcomes among Stage III \& IV patients with squamous cell carcinomas (SCCa) of the oropharynx treated with definitive radiation therapy (RT), with concurrent chemotherapy.

\section{Method}

This is a retrospective analysis of patients with stage III \& IV SCCa of oropharynx treated with definitive RT at the State Academic Medical Center. All patients were treated to $70 \mathrm{~Gy}$ utilizing intensity-modulated radiation treatment (IMRT), and received concurrent chemotherapy with weekly cisplatin or cetuximab. Chisquare test was used to test the goodness of fit, overall survival (OS), and locoregional control (LRC) comparing races were generated by using Log-rank test \& Kaplan-Meier method. The covariables associated with the OS and LRC were determined by the Cox regression model. A p-value of less than 0.05 was considered statistically significant. The SPSS 24.0 software (IBM Corp., Armonk, NY) was used.

\section{Results}

In the total 73 eligible patients, $54.8 \%$ were black, and $45.2 \%$ white patients. Stage distribution (per American Joint Committee on Cancer-AJCC $8^{\text {th }}$ Ed) between black patients vs. white patients, Stage III (45.5\% vs. $54.5 \%$ ) and for Stage IV (56.5\% vs. $43.5 \%$ ); $\mathrm{p}=0.499$. Median follow-up for the entire group was 41 months (range: 4-144 months). In the univariate analysis, variables p16 status, body mass index (BMI), alcohol history and tumor subsite were found to be significant. In the multivariate analysis, only BMI has shown to be significant.

Review began 02/04/2021 Review ended 02/25/2021 Published 03/03/2021

\section{(๑) Copyright 2021}

Nittala et al. This is an open access article distributed under the terms of the Creative Commons Attribution License CC-BY 4.0., which permits unrestricted use, distribution, and reproduction in any medium, provided the original author and source are credited.
Three-year LRC for black patients was $37.8 \%$ vs. $66.8 \%$ in white patients ( $\mathrm{p}=0.354$ ) and three-year OS for black patients was $51.8 \%$ vs. $80.9 \%$ for white patients $(\mathrm{p}=0.063$ ), respectively. Five-year OS for $\mathrm{p} 16$ positive patients was $69.7 \%$ vs. $43 \%$ for $\mathrm{p} 16$ negative patients ( $\mathrm{p}=0.034)$. Five-year OS for Stage IV black patients was $34 \%$ vs. $69.5 \%$ for Stage IV white patients $(\mathrm{p}=0.014)$.

\section{Conclusion}

Among all the co-variables examined, only BMI has shown affecting the OS outcomes; gender and BMI shown to be affecting the LRC. Racial factor appears to be significant in Stage IV patients.

Categories: Radiation Oncology, Public Health, Epidemiology/Public Health

Keywords: oropharyngeal carcinoma, racial disparities, hpv/p16

\section{Introduction}

Oropharyngeal squamous cell carcinomas (SCCa) include cancers of the base of the tongue, the palatine tonsils, the soft palate, and the posterior oropharyngeal wall [1], and it is the sixth most commonly diagnosed cancers in the United States [2], accounting for 3\% of all new cases of cancer in the United States [3]. In previous studies, the increased incidences of oropharyngeal cancers has been strongly associated with tobacco and alcohol exposure but it's been noted that incidence of oropharyngeal SCCa is high among middle-aged nonsmokers or light smokers male whites compared with older men with a significant history of drinking and smoking [4-7]. Approximately 75\% of newly diagnosed oropharyngeal SCCa cases are related to human papillomavirus (HPV) [8,9]. According to the Center for Disease Control and Prevention (CDC), each year about 14,800 new HPV/p16- related oropharyngeal SCCa cases are diagnosed in 
men and 3,400 in women [10]. About 8.8 men and 1.8 women per 100,000 were diagnosed with HPV/p16related oropharyngeal SCCa among white people, and 6.6 men and 1.4 women per 100,000 among black people [10]. Black people are less likely to have HPV/p16-related oropharyngeal SCCa therefore, black patients have shown to be associated with poor overall survival (OS) when compared to white patients $[11,12]$. The racial disparities among oropharyngeal cancers reflect the interplay of age, gender, socioeconomic factors, culture, diet, stress, state of residence, the environment and biology $[13,14]$.

The aim of this study is to investigate the OS and locoregional control (LRC) of advanced-stage oropharyngeal SCCa treated at the University of Mississippi Medical Center (UMMC), and whether these differences are related to patient race, tumor characteristics and or socioeconomic status (SES).

This article was previously presented as a scientific meeting abstract at the 2019 AACR-AHNS Head and Neck Cancer Conference at Austin, TX, USA on April 29, 2019 (DOI: 10.1158/1557-3265.AACRAHNS19-B21).

\section{Materials And Methods}

\section{Patients}

An institutional review board (IRB \# 2010-0252) approval was obtained for retrospective analysis of oropharyngeal SCCa patients treated by definitive RT, with concurrent chemotherapy from 2011 to 2018 at UMMC, Jackson, MS, USA. We used the browser-based database tool Research electronic data capture (RedCap) to gather and store the patient's information in password-protected computers. All the patient's details for demographics, disease presentation, disease staging, treatments, and complications were recorded at the time of their enrollment in the database. Patient identifiers were removed before extracting the data. All the patient's histology is identified as SCCa by biopsy and selected only Stages III \& IV. The variables race, gender, smoking and alcohol history were self-reported. The variables weight, body mass index (BMI) were measured before and after treatment. All the demographic variables, disease presentation, disease staging (AJCC stage 8th edition), treatments, and complications for each patient were recorded. Sample size $(n=73)$ with $80 \%$ power to detect the factors affecting the survival in this study was estimated by using sample size calculator.

\section{Treatment methods}

All patients were treated to 70 Gy utilizing intensity-modulated radiation treatment (IMRT), and all patients received concurrent chemotherapy with weekly cisplatin, $40 \mathrm{mg} / \mathrm{m}^{2}$ (61.6\%) or weekly cetuximab, $400 \mathrm{mg} / \mathrm{m}^{2}$ (38.4\%). All the treatment plans were evaluated by departmental peer review before the initiation [15]. HPV infection was confirmed to be positive, if $70 \%$ or more of the tumor cells show cytoplasmic and nuclear staining for p16 [16,17].

\section{Statistical analysis}

Fisher test is used to evaluate the racial comparison between black patients and white patients. OS for all the 73 patients in the cohort were calculated from the date of disease diagnosis and the patients last contact date. To evaluate the OS and LRC, Kaplan-Meier method was used and the comparison between black patients \& white patients was measured by the log-rank test. The covariables associated with the OS and LRC were determined by the univariate and multivariate Cox regression model. Hazards ratio (HR) were estimated by time to event outcome with associated $95 \%$ confidence intervals (CIs) and p-values $\leqslant 0.05$ were considered significant. The SPSS 24.0 software (IBM Corp., Armonk, NY) was used for data analysis.

\section{Results}

\section{Patient characteristics}

This study includes a total of 73 patients with SCCa of the oropharynx treated from 2011 to 2018 at UMMC. The median follow-up was 41 months (range: 4 to 144 months). Among the total 73 eligible patients, 54.8\% were black patients, and $45.2 \%$ were white patients (Figure 1). Summary of patient's demographic and clinical description was represented in (Table 1). There was no significant difference in gender or sex, age, BMI, employment status, distance traveled to the treatment facility, marital status smoking and alcohol history between black patients and white patients. 


\section{Cureus}

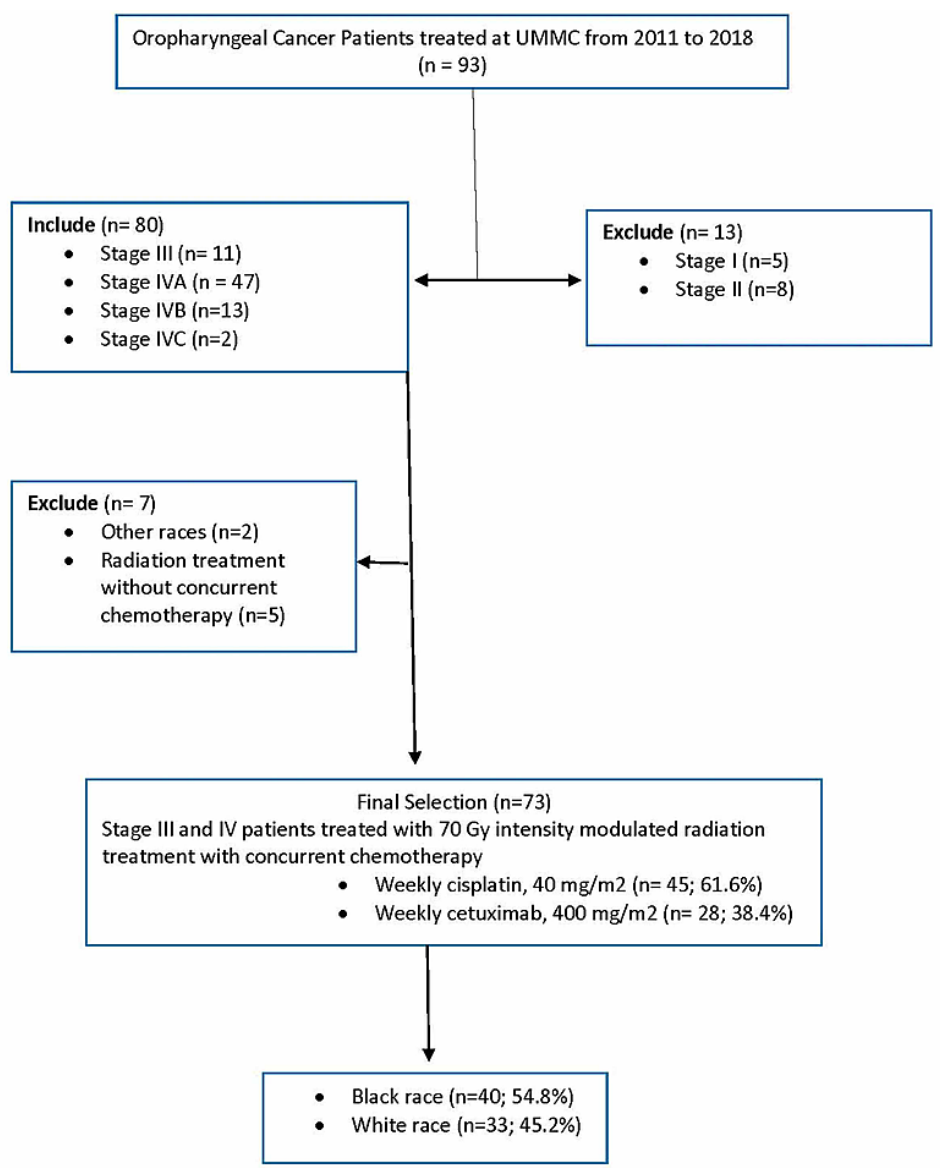

\section{FIGURE 1: Consort diagram of patients included.}

UMMC: University of Mississippi Medical Center.

Black race $(n=40 ; 54.8 \%) \quad$ White race $(n=33 ; 45.2 \%)$

All patients $(n=73 ; 100 \%)$

p-value

Gender/sex

Male

$30(75.0 \%)$

$10(25.0 \%)$

$6(15.0 \%)$

$3(9.1 \%)$

$9(12.3 \%)$

0.445

$34(85.0 \%)$

$30(90.9 \%)$

$64(87.7 \%)$

BMI

Underweight (under $18.5 \mathrm{~kg} / \mathrm{m}^{2}$ ) $18(45.0 \%)$

$8(24.2 \%)$

$16(21.9 \%)$

0.223

Normal (18.5 to $\left.24.9 \mathrm{~kg} / \mathrm{m}^{2}\right) \quad 9(22.5 \%)$

$7(21.2 \%)$

$26(35.6 \%)$

Overweight (25.0 to $\left.29.9 \mathrm{~kg} / \mathrm{m}^{2}\right) \quad 5(12.5 \%)$

$8(20.0 \%)$

$8(24.2 \%)$

$13(17.8 \%)$

Obese (over $30.0 \mathrm{~kg} / \mathrm{m}^{2}$ )

Income quartile

$<\$ 35000$ - Low Income

$25(62.5 \%)$

$12(36.4 \%)$

$37(50.7 \%)$

0.026

$21(63.6 \%)$

36 (49.3\%) 


\section{Cureus}

\begin{tabular}{|c|c|c|c|c|}
\hline \multicolumn{5}{|l|}{ Insurance } \\
\hline Medicaid & $22(55.0 \%)$ & $10(30.3 \%)$ & $32(43.8 \%)$ & 0.072 \\
\hline Medicare & $9(22.5 \%)$ & 9 (27.3\%) & $18(24.7 \%)$ & \\
\hline Private & $6(15.0 \%)$ & $5(15.2 \%)$ & $11(15.1 \%)$ & \\
\hline Self-pay & $3(7.5 \%)$ & $9(27.3 \%)$ & $12(16.4 \%)$ & \\
\hline \multicolumn{5}{|l|}{ Employment } \\
\hline Employed & 12 (30.0\%) & 9 (27.3\%) & $21(28.8 \%)$ & 0.798 \\
\hline Unemployed & $28(70.0 \%)$ & $24(72.7 \%)$ & $52(71.2 \%)$ & \\
\hline \multicolumn{5}{|l|}{ Distance from facility } \\
\hline$<25$ miles & 7 (17.5\%) & $8(24.2 \%)$ & $15(20.5 \%)$ & 0.147 \\
\hline $26-50$ miles & $7(17.5 \%)$ & $3(9.1 \%)$ & $10(13.7 \%)$ & \\
\hline 51-100 miles & $17(42.5 \%)$ & $8(24.2 \%)$ & 25 (34.2\%) & \\
\hline$>100$ miles & $9(22.5 \%)$ & $14(42.4 \%)$ & $23(31.5 \%)$ & \\
\hline \multicolumn{5}{|l|}{ Smoking status } \\
\hline Smoker & 37 (92.5\%) & $29(87.9 \%)$ & $66(90.4 \%)$ & 0.505 \\
\hline Non-smoker & $3(7.5 \%)$ & $4(12.1 \%)$ & $7(9.6 \%)$ & \\
\hline \multicolumn{5}{|l|}{ Alcohol status } \\
\hline Drinker & 29 (72.5\%) & $21(63.6 \%)$ & $50(68.5 \%)$ & 0.417 \\
\hline Non-drinker & $11(27.5 \%)$ & $12(36.4 \%)$ & $23(31.5 \%)$ & \\
\hline \multicolumn{5}{|l|}{ Marital status } \\
\hline Single & $25(62.5 \%)$ & $19(57.6 \%)$ & $44(60.3 \%)$ & 0.669 \\
\hline Married & $15(34.2 \%)$ & $14(42.4 \%)$ & 29 (39.7\%) & \\
\hline \multicolumn{5}{|l|}{ HPV/p16 status } \\
\hline Negative & $32(80.0 \%)$ & $17(51.5 \%)$ & $49(67.1 \%)$ & 0.010 \\
\hline Positive & $8(20.0 \%)$ & $16(48.5 \%)$ & 24 (32.9\%) & \\
\hline \multicolumn{5}{|l|}{ Subsite } \\
\hline Posterior oropharyngeal wall & $5(12.5 \%)$ & $3(9.1 \%)$ & $8(11.0 \%)$ & 0.425 \\
\hline BOT & $4(10.0 \%)$ & $1(3.0 \%)$ & $5(6.8 \%)$ & \\
\hline Palatine tonsil & $31(77.5 \%)$ & $29(87.9 \%)$ & 60 (82.2\%) & \\
\hline \multicolumn{5}{|l|}{ T stage } \\
\hline T0 & $0(0.0 \%)$ & $0(0.0 \%)$ & $0(0.0 \%)$ & N/A \\
\hline T1 & $3(7.5 \%)$ & $9(27.3 \%)$ & 12 (16.4\%) & 0.023 \\
\hline T2 & $16(40.0 \%)$ & $12(36.4 \%)$ & $28(38.4 \%)$ & 0.750 \\
\hline T3 & 5 (12.5\%) & 5 (15.2\%) & 10 (13.7\%) & 0.743 \\
\hline T4 & 16 (21.9\%) & 6 (8.2\%) & 22 (30.1\%) & 0.043 \\
\hline \multicolumn{5}{|l|}{ N stage } \\
\hline No & $5(12.5 \%)$ & $3(9.1 \%)$ & $8(11.0 \%)$ & 0.643 \\
\hline N1 & 2 (5.0\%) & 5 (15.2\%) & 7 (9.6\%) & 0.143 \\
\hline N2 & 27 (67.5\%) & $22(66.7 \%)$ & $49(67.1 \%)$ & 0.940 \\
\hline N3 & 6 (15.0\%) & 2 (6.1\%) & $8(11.0 \%)$ & 0.224 \\
\hline
\end{tabular}




\section{Cureus}

\begin{tabular}{|c|c|c|c|c|}
\hline \multicolumn{5}{|l|}{ M stage } \\
\hline MO & 38 (95.0\%) & 32 (97.0\%) & 70 (95.9\%) & 0.673 \\
\hline M1 & $2(5.0 \%)$ & $0(0.0 \%)$ & $2(2.7 \%)$ & 0.386 \\
\hline Unknown & $0(0.0 \%)$ & 1 (3.0\%) & 1 (1.4\%) & $\mathrm{N} / \mathrm{A}$ \\
\hline \multicolumn{5}{|c|}{ Overall stage } \\
\hline III & 5 (12.5\%) & 6 (18.2\%) & 11 (15.1\%) & 0.499 \\
\hline IV & 35 (87.5\%) & 27 (81.8\%) & $62(84.9 \%)$ & \\
\hline
\end{tabular}

\section{TABLE 1: Demographic and clinical characteristics of the study population by race.}

BMI: body mass index; BOT: base of tongue; HPV: human papillomavirus; n: number.

A significant relationship between income quartile $(\mathrm{p}=0.026)$, and $\mathrm{p} 16$ status $(\mathrm{p}=0.010)$ was identified among different races (Table 1); however, there were no racial differences in tumor location and cancer stage at the time of diagnosis. Regarding the income quartile, where both the races showed statistically significant $(\mathrm{p}=0.026)$, the majority of black patients $(62.5 \%)$ belong to lower-income quartile and the majority of white patients to higher-income quartile (63.6\%). For the $\mathrm{p} 16$ status $(\mathrm{p}=0.010)$, black patients showed a majority of p16 negative (80.0\%) compared to white patients (51.5\%), and white patients showed $48.5 \%$ of p16 positive compared to $20 \%$ among black patients.

\section{Cox regression analysis for overall survival}

In the univariate OS Cox regression analysis, variables like BMI, p16 status, alcohol history, and tumor subsites showed a statistically significant difference in disease prognosis (Table 2).

\begin{tabular}{|c|c|c|c|c|}
\hline & \multicolumn{2}{|l|}{ Univariable } & \multicolumn{2}{|l|}{ Multivariable } \\
\hline & HR (95 \% Cl) & $\mathrm{p}$-value & HR (95\% Cl) & $\mathrm{p}$-value \\
\hline \multicolumn{5}{|l|}{ Gender/sex } \\
\hline Male & 1 & & - & \\
\hline Female & $1.32(0.54-3.21)$ & 0.541 & - & - \\
\hline \multicolumn{5}{|l|}{ Age } \\
\hline$<50$ years & 1 & & - & \\
\hline$>50$ years & $1.06(0.37-3.03)$ & 0.906 & - & - \\
\hline \multicolumn{5}{|l|}{ Ethnicity } \\
\hline Black race & 1 & & - & \\
\hline White race & $1.93(0.95-3.94)$ & 0.069 & - & - \\
\hline \multicolumn{5}{|l|}{ BMI } \\
\hline Normal (18.5 to $25 \mathrm{~kg} / \mathrm{m}^{2}$ ) & 1 & & 1 & \\
\hline Underweight (under $18.5 \mathrm{~kg} / \mathrm{m}^{2}$ ) & $3.18(0.84-12.04)$ & 0.088 & $2.50(0.63-9.91)$ & 0.192 \\
\hline Overweight ( 25.0 to $29.9 \mathrm{~kg} / \mathrm{m}^{2}$ ) & $6.72(1.97-22.88)$ & 0.002 & $4.75(1.31-17.24)$ & 0.018 \\
\hline Obese (over $30.0 \mathrm{~kg} / \mathrm{m}^{2}$ ) & $1.35(0.27-6.70)$ & 0.711 & $1.24(0.24-6.21)$ & 0.792 \\
\hline \multicolumn{5}{|l|}{ Income quartile } \\
\hline$<\$ 35,000$ - low income & 1 & & - & \\
\hline$>35,000$ & $1.08(0.54-2.15)$ & 0.815 & - & - \\
\hline Insurance & & & & \\
\hline
\end{tabular}




\section{Cureus}

\begin{tabular}{|c|c|c|c|c|}
\hline \multirow{2}{*}{$\begin{array}{l}\text { Medicaid } \\
\text { Medicare }\end{array}$} & \multicolumn{2}{|l|}{1} & \multicolumn{2}{|l|}{ - } \\
\hline & $1.81(0.60-5.44)$ & 0.288 & - & - \\
\hline Private & $1.56(0.49-4.92)$ & 0.448 & - & - \\
\hline Self-pay & $0.86(0.19-3.85)$ & 0.845 & - & - \\
\hline \multicolumn{5}{|l|}{ Employment } \\
\hline Employed & 1 & & - & \\
\hline Unemployed & $0.43(0.17-1.04)$ & 0.064 & - & - \\
\hline \multicolumn{5}{|l|}{ Distance from facility } \\
\hline$<25$ miles & 1 & & - & \\
\hline 26-50 miles & $0.50(0.17-1.45)$ & 0.204 & - & - \\
\hline 51-100 miles & $1.35(0.49-3.67)$ & 0.557 & - & - \\
\hline$>100$ miles & $0.85(0.37-1.94)$ & 0.706 & - & - \\
\hline \multicolumn{5}{|l|}{ Smoking status } \\
\hline Yes & 1 & & - & \\
\hline No & $0.04(0.00-3.57)$ & 0.176 & - & - \\
\hline \multicolumn{5}{|l|}{ Alcohol status } \\
\hline Yes & 1 & & - & \\
\hline No & $0.37(0.14-0.96)$ & 0.042 & $0.38(0.14-1.03)$ & 0.059 \\
\hline \multicolumn{5}{|l|}{ Marital status } \\
\hline Single & 1 & & - & \\
\hline Married & $1.01(0.50-2.03)$ & 0.974 & - & - \\
\hline \multicolumn{5}{|l|}{ HPV/p16 status } \\
\hline Negative & 1 & & 1 & \\
\hline Positive & $0.41(0.18-0.96)$ & 0.040 & $0.65(0.26-1.62)$ & 0.362 \\
\hline \multicolumn{5}{|l|}{ Subsite } \\
\hline Posterior oropharyngeal wall & 1 & & 1 & \\
\hline BOT & $2.91(1.18-7.16)$ & 0.020 & $1.96(0.74-5.13)$ & 0.171 \\
\hline Palatine tonsil & $1.00(0.23-4.25)$ & 1.000 & $0.78(0.18-3.37)$ & 0.746 \\
\hline \multicolumn{5}{|l|}{ Overall stage } \\
\hline III & 1 & & - & - \\
\hline IV & $0.63(0.22-1.79)$ & 0.388 & - & - \\
\hline
\end{tabular}

\section{TABLE 2: Univariable and multivariable Cox regression for overall survival.}

BMI: body mass index; BOT: base of tongue; HPV: human papillomavirus; Cl: confidence interval.

Regarding BMI, the overweight patients (25.0 to $29.9 \mathrm{~kg} / \mathrm{m}^{2}$ ) presented six times the risk of death (HR 6.72, $95 \% \mathrm{CI}, 1.97-22.88 ; \mathrm{p}=0.002$ ), and the patients with no alcohol history presented a $63 \%$ decreased risk of death (HR 0.37, 95\% CI, 0.14-0.96; $\mathrm{p}=0.042$ ); neither income quartile nor the health insurance showed any statistical significance. Variables like employment status, distance traveled to the facility, smoking status, and marital status did not show any significance statistically.

In the univariate analysis considering the tumor characteristics, p16 status and tumor subsites showed 


\section{Cureus}

statistical significance in the prognosis. The p16 positive patients showed $59 \%$ decreased risk of mortality (HR 0.41, 95\% CI, 0.18-0.96; $\mathrm{p}=0.040$ ) compared to $\mathrm{p} 16$ negative patients (Table 2). The base of tongue (BOT) presented twice the risk of dying from oropharyngeal SCCa (HR 2.91, 95\% CI, 1.18-7.16; $\mathrm{p}=0.020$ ) compared to posterior oropharyngeal wall and palatine tonsils. Overall tumor staging did not significantly influence the overall survival of the patients (Table 2).

The multivariate Cox regression was built in which all the significant variables, BMI, p16 status, alcohol history, and tumor subsites were added in the model. It is interesting to notice that BMI is the only variable that showed the statistical significance and the risk is reduced 30\% in the multivariate model (HR 4.75, 95\%

CI, 1.31-17.24; $\mathrm{p}=0.018)$. The patients with overweight BMI $\left(25.0\right.$ to $\left.29.9 \mathrm{~kg} / \mathrm{m}^{2}\right)$ showed almost five times the risk of dying from oropharyngeal SCCa (HR 4.75, 95\% CI, 1.31-17.24; $\mathrm{p}=0.018$ ) (Table 2).

\section{Cox regression analysis for locoregional control}

In the univariate Cox regression analysis for LRC, variables like gender, and BMI showed a statistically significant difference in disease prognosis. When analyzed by gender, female demonstrated twice the risk of death from the oropharyngeal cancer compared to males (HR 2.08, 95\% CI, 1.03-4.23; p=0.041). Regarding BMI, the overweight patients ( 25.0 to $29.9 \mathrm{~kg} / \mathrm{m}^{2}$ ) presented twice the risk of relapsing oropharyngeal SCCa (HR 1.98, 95\% CI, 1.01-3.90; $\mathrm{p}=0.047$ ) (Table 3).

\begin{tabular}{|c|c|c|c|c|}
\hline & \multicolumn{2}{|l|}{ Univariable } & \multicolumn{2}{|l|}{ Multivariable } \\
\hline & HR (95\% Cl) & p-value & HR (95\% Cl) & p-value \\
\hline \multicolumn{5}{|l|}{ Gender/sex } \\
\hline Male & 1 & & 1 & \\
\hline Female & $2.08(1.03-4.23)$ & 0.041 & $2.65(1.25-5.60)$ & 0.010 \\
\hline \multicolumn{5}{|l|}{ Age } \\
\hline$<50$ years & 1 & & - & \\
\hline$>50$ years & $1.04(0.49-2.21)$ & 0.901 & - & - \\
\hline \multicolumn{5}{|l|}{ Ethnicity } \\
\hline Black race & 1 & & - & \\
\hline White race & $1.24(0.74-2.07)$ & 0.410 & - & - \\
\hline \multicolumn{5}{|l|}{ BMI } \\
\hline Normal (18.5 to $24.9 \mathrm{~kg} / \mathrm{m}^{2}$ ) & 1 & & 1 & \\
\hline Underweight (under $18.5 \mathrm{~kg} / \mathrm{m}^{2}$ ) & $1.10(0.52-2.32)$ & 0.788 & $1.31(0.61-2.81)$ & 0.476 \\
\hline Overweight (25.0 to $\left.29.9 \mathrm{~kg} / \mathrm{m}^{2}\right)$ & $1.98(1.01-3.90)$ & 0.047 & $2.76(1.32-5.76)$ & 0.007 \\
\hline Obese (over 30.0 kg/m²) & $0.80(0.37-1.72)$ & 0.580 & $0.98(0.45-2.12)$ & 0.969 \\
\hline \multicolumn{5}{|l|}{ Income quartile } \\
\hline$<\$ 35,000$ - low income & 1 & & - & \\
\hline$>35,000$ & $1.02(0.61-1.69)$ & 0.934 & - & - \\
\hline \multicolumn{5}{|l|}{ Insurance } \\
\hline Medicaid & 1 & & - & \\
\hline Medicare & $1.18(0.55-2.52)$ & 0.653 & - & - \\
\hline Private & $0.50(0.21-1.19)$ & 0.12 & - & - \\
\hline Self-pay & $0.78(0.29-2.05)$ & 0.621 & - & - \\
\hline \multicolumn{5}{|l|}{ Employment } \\
\hline Employed & 1 & & - & \\
\hline Unemployed & $0.58(0.32-1 / 05)$ & 0.073 & - & - \\
\hline
\end{tabular}




\section{Cureus}

Distance from facility

$<25$ miles 1

26-50 miles

$0.56(0.26-1.18)$

0.128

51-100 miles

1.64 (0.72-3.72)

0.232

$>100$ miles

$0.73(0.39-1.37)$

0.339

Smoking Status

Yes

1

No

$0.73(0.31-1.71)$

0.476

Alcohol status

Yes

1

No

0.79 (0.46-1.36)

0.410

Marital status

Single

1

Married

$0.81(0.48-1.36)$

0.431

HPV/p16 status

Negative

1

\section{Positive}

$0.81(0.46-1.40)$

0.451

Subsite

Posterior oropharyngeal wall

1

BOT

$1.53(0.65-3.60)$

0.326

Palatine tonsil

$1.65(0.58-4.69)$

0.341

Overall stage

III

1

IV

$0.57(0.27-1.21)$

0.148

TABLE 3: Univariable and multivariable Cox regression for locoregional control.

BMI: body mass index; BOT: base of tongue; HPV: human papillomavirus; $\mathrm{Cl}$ : confidence interval.

In the multivariate analysis, variables like gender, and BMI both showed the statistical significance and the LRC risk in gender/female is increased 3 times (HR 2.65; 95\% CI, 1.25-5.60; $\mathrm{p}=0.010$ ) and the patients with overweight BMI (25.0 to $29.9 \mathrm{~kg} / \mathrm{m}^{2}$ ) showed almost three times the risk of death (HR 2.76; 95\% CI, 1.32-5.76; $\mathrm{p}=0.007$ ) (Table 3).

\section{Kaplan-Meier curves for overall survival and locoregional control}

The 16 negative patients showed statistically significant worse 5 -year OS compared to $\mathrm{p} 16$ positive patients, $43 \%$ vs. $69.7 \%$ ( $\mathrm{p}=0.034$ ). Median follow-up for the entire group was 41 months (range: 4-144 months). Kaplan-Meier survival curves were shown in Figures 2-8. The alcohol history, tumor subsites and p16 status, were all independently associated with statistically significant OS rates. For Stage IV, the black patients showed statistically significant worse five-year OS compared to white patients, $34 \%$ vs. $69.5 \%$ $(\mathrm{p}=0.014)$. 


\section{Cureus}

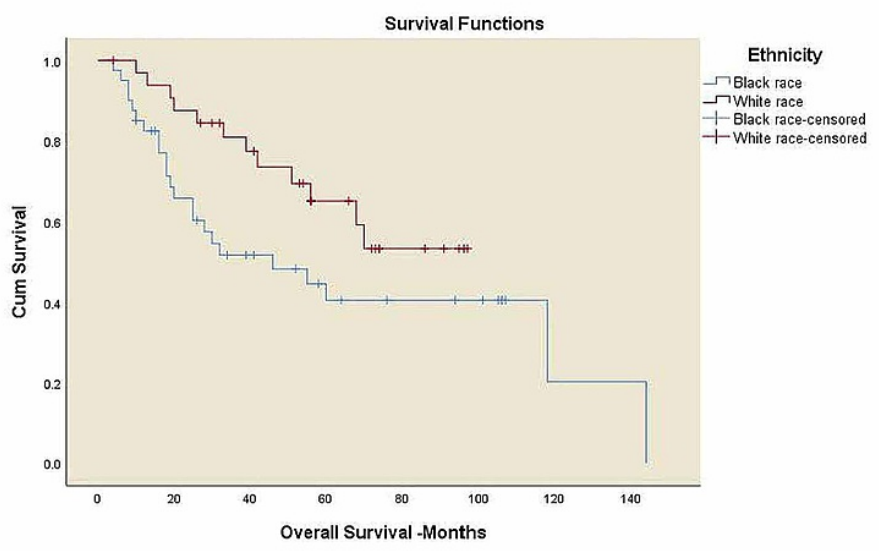

FIGURE 2: Overall Survival for all patients by race/ethnicity.

OS: overall survival. Black race: five-year OS $40.6 \%$, white race: five-year OS $65.3 \%, p=0.063$.

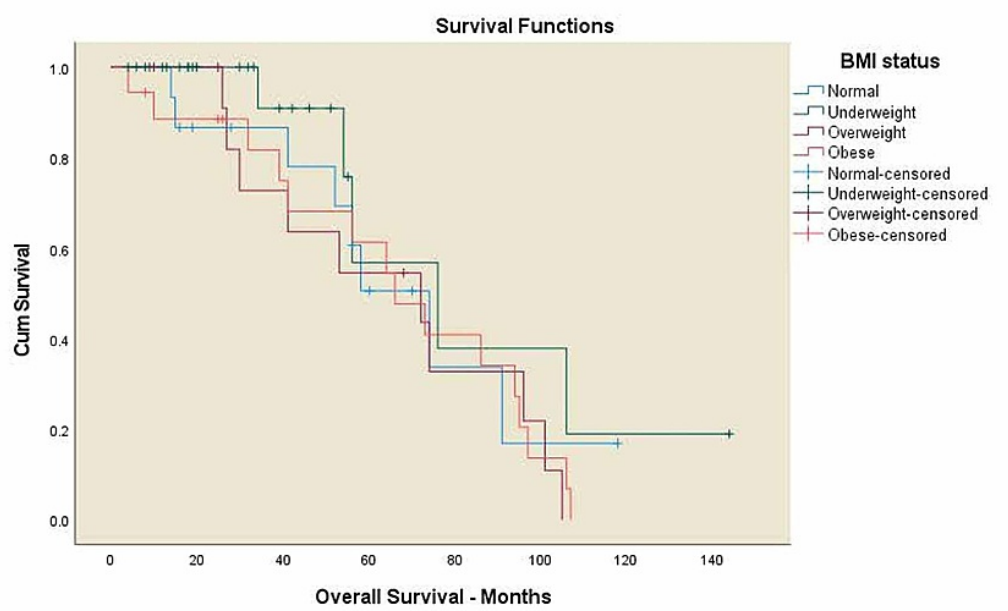

FIGURE 3: Overall survival for all patients by BMI.

BMI: body mass index; OS: overall survival. Normal weight: five-year OS 50.6\%, underweight: five-year OS $56.8 \%$, overweight: five-year OS $43.6 \%$, obese: five-year OS $51.3 \%, p=0.425$. 


\section{Cureus}

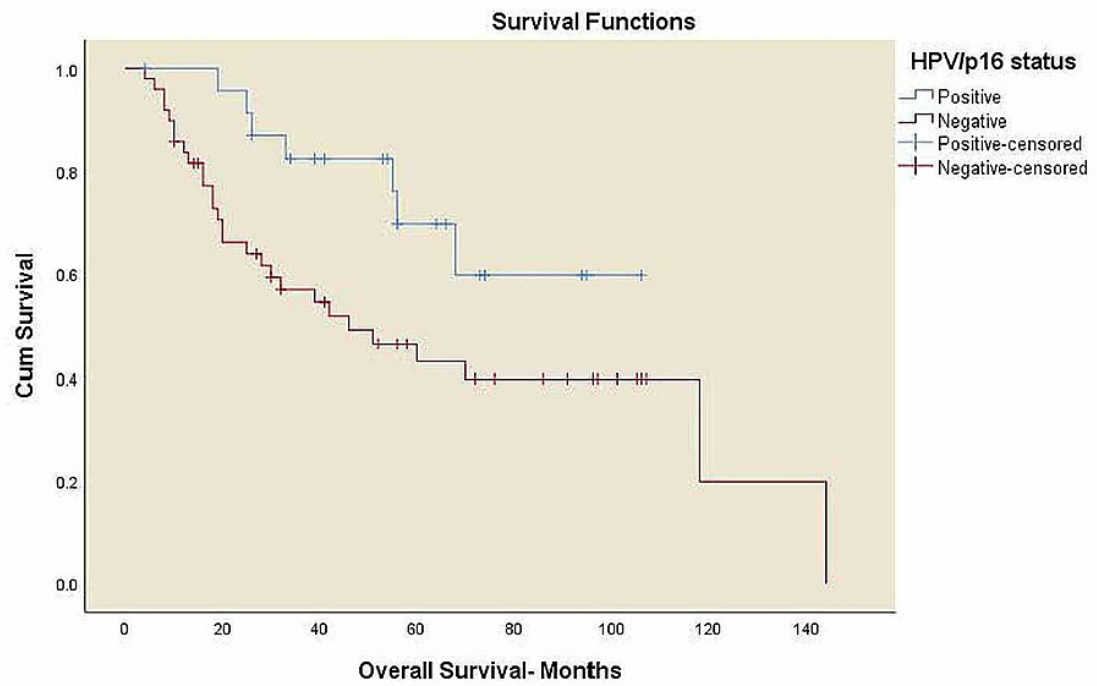

FIGURE 4: Overall survival for all patients by HPV/p16 status.

HPV: human papillomavirus, OS: overall survival. HPV/p16 positive: five-year OS $69.7 \%$, HPV/p16 negative: five-year OS $43 \%, p=0.034$.

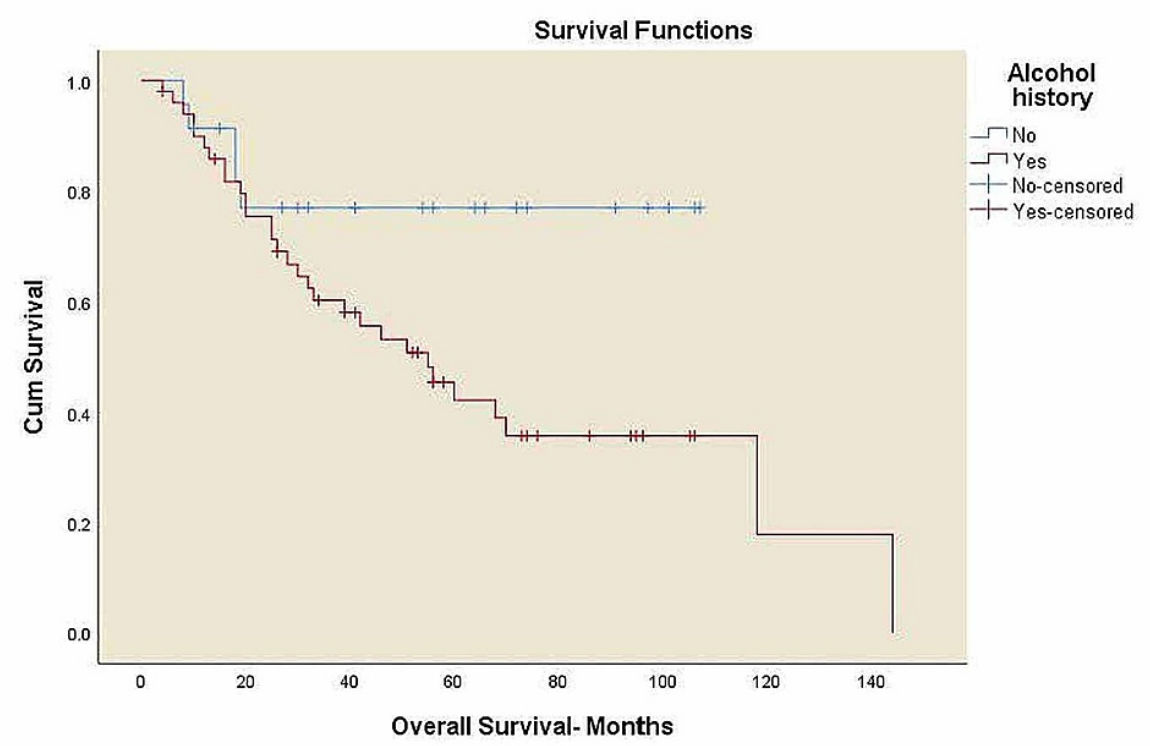

FIGURE 5: Overall survival for all patients by alcohol history.

OS: overall survival, without alcohol history: five-year OS $76.9 \%$, with alcohol history: five-year OS $42.3 \%$, $\mathrm{p}=0.034$. 


\section{Cureus}

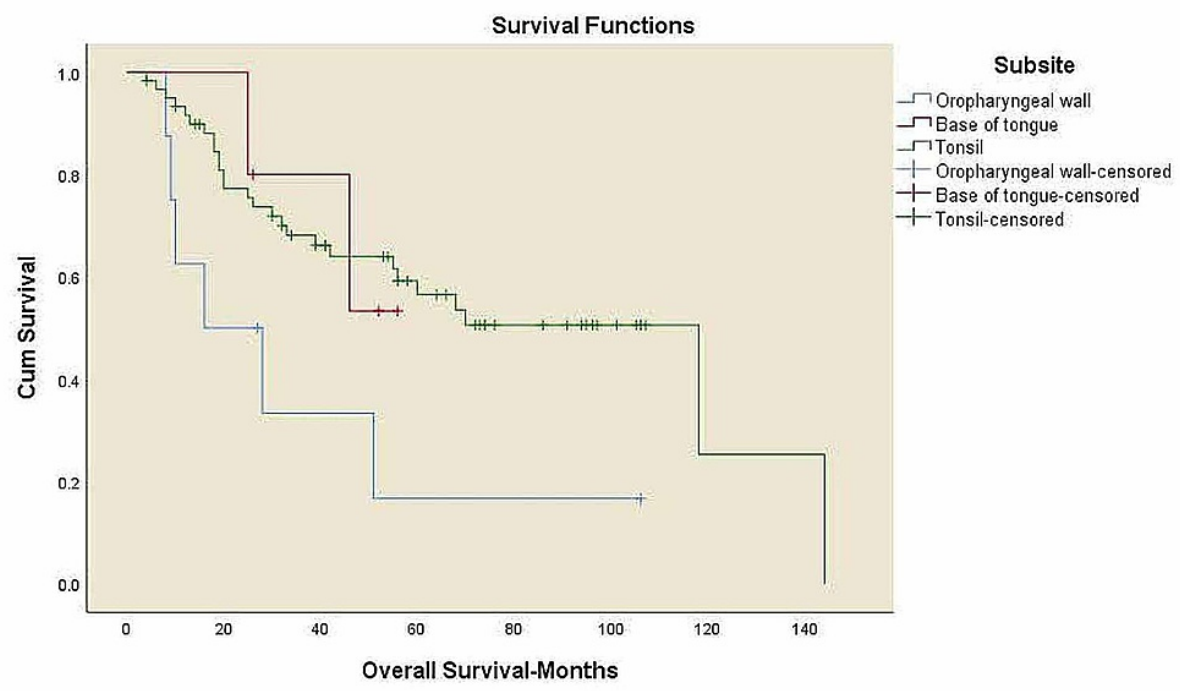

FIGURE 6: Overall survival for all patients by tumor subsite.

OS: overall survival. Oropharyngeal wall: five-year OS $16.7 \%$, base of tongue: five-year OS $53.3 \%$, tonsil: five-year OS $56.5 \%$, $\mathrm{p}=0.047$.

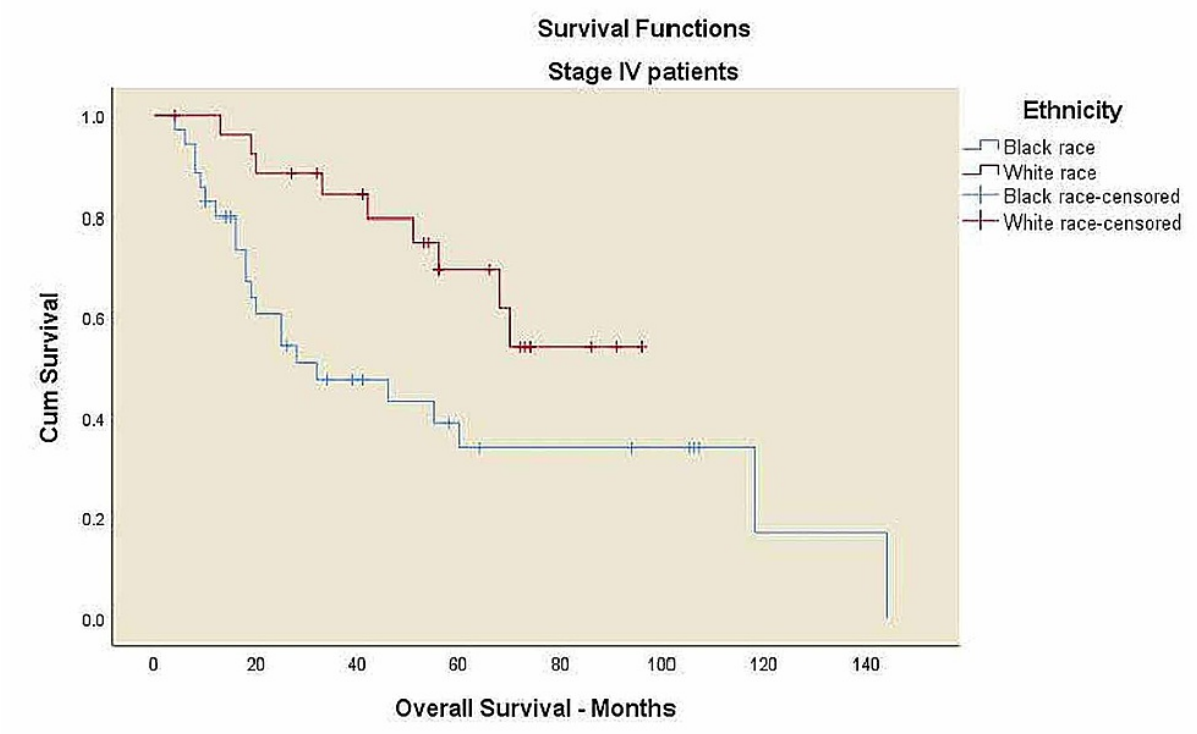

FIGURE 7: Overall survival for Stage IV patients by ethnicity.

OS: overall survival. Black race: five-year OS $34 \%$, white race: five-year OS $69.5 \%, p=0.014$. 


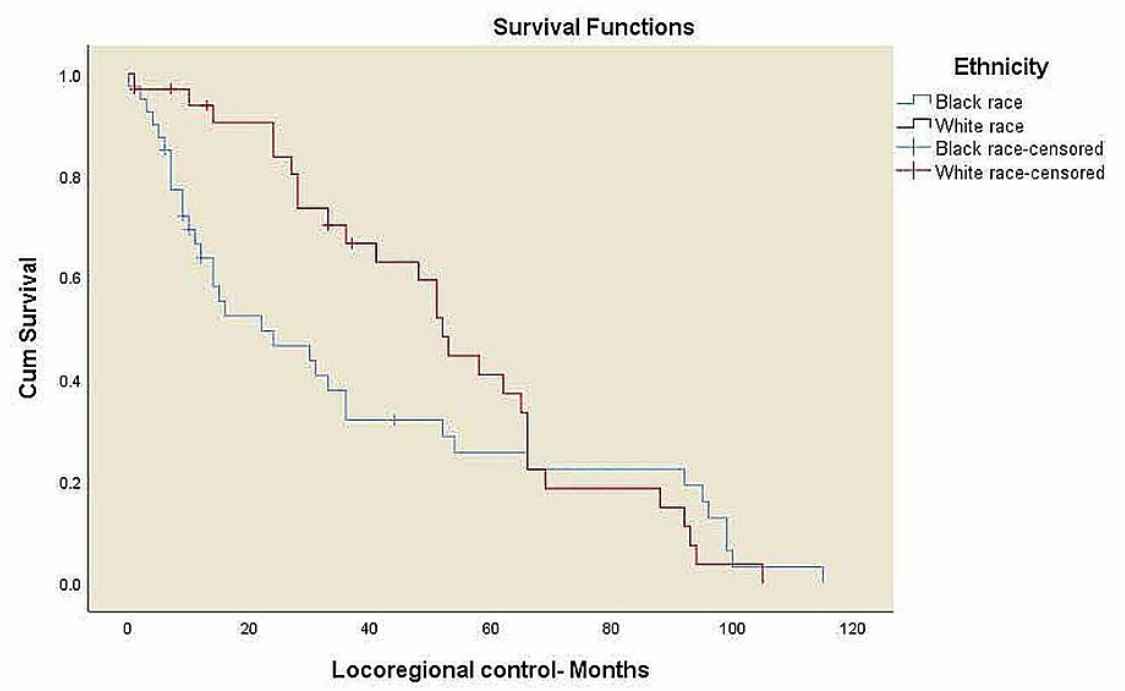

\section{FIGURE 8: Locoregional control for all patients by race/ethnicity.}

LRC: locoregional control. Black race: three-year LRC 37.8\%, white race: three-year LRC $66.8 \%, p=0.354$.

There was a trend toward worse OS among black patients compared to white patients, $41 \%$ vs. $65 \%$ $(\mathrm{p}=0.063)$, and decreased survival in overweight patients compared to normal-weight patients, $43.6 \%$ vs. $50.6 \%(\mathrm{p}=0.425)$ with no statistical significance. A significant trend towards decreased survival in patients with alcohol history compared to the patients without alcohol history, $42.3 \%$ vs. $76.9 \%$ ( $\mathrm{p}=0.034)$, and a decreased survival rates in $\mathrm{p} 16$ negative patients compared to $\mathrm{p} 16$ positive patients, $43 \%$ vs. $69.7 \%$ ( $\mathrm{p}=0.034)$ was noticed. Three-year LRC for black patients was $37.8 \%$ vs. $66.8 \%$ in white patients $(\mathrm{p}=0.354)$ with no statistical significance.

\section{Discussion}

In this retrospective study of 73 oropharyngeal SCCa patients, we evaluated variables, socio-demographic individual characteristics (race/ethnicity, age, gender, BMI, marital status, health insurance); clinical characteristics (tumor site, tumor grade and p16 status); county-level SES attributes (age distribution, unemployment, income, distance traveled to treatment facility, smoking, and alcohol history).

We found the following important findings.

Our study found no statistically significant difference in survival outcomes between black and white patients' among Stage III \& IV SCCa. This may be due to few numbers of patients in Stage III (15.1\% vs. 84.9\%) compared to Stage IV. However, racial factor appears to be significant in Stage IV patients, the black patients showed statistically significant worse 5 -year OS compared to white patients, $34 \%$ vs. $69.5 \%$ $(\mathrm{p}=0.014)$.

Our study reports that overweight patients show statistically significant increased risk of death compared to normal weight patients, (HR 4.75, 95\% CI, 1.31-17.24; $\mathrm{p}=0.018$ )

Our study demonstrates that patients with alcohol history show a statistically significant worse survival compared to the patients without alcohol history, $42.3 \%$ vs. $76.9 \%(\mathrm{p}=0.034)$.

Our study observed a trend of statistically significant worse survival for $\mathrm{p} 16$ negative patients compared to p16 positive patients, $43 \%$ vs. $69.7 \%$ ( $\mathrm{p}=0.034)$.

In our study population, white patients present overall the best distribution according to the patient, tumor, socioeconomic and county-level attributes, similar to previous studies where black patients were more frequently presented with the least favorable distribution [18]. Many studies reported that the association of the black population with lower household income, lower employment rates are more likely associated with increased rates of smoking and heavy alcohol use $[19,20]$. Our study found no statistical difference in survival outcomes between the black patients and the white patients, because of few numbers of patients in Stage III compared to Stage IV. However, in Stage IV, black patients showed statistically significant worse 
survivals compared to their white counterparts.

The smoking and alcohol consumption rates were similar between white and black patients; however, in overall cohort, the patients with alcohol history demonstrated worse survival compared to the patients without alcohol history. Black oropharyngeal SCCa patients are more likely to reside in lower education and lower-income level and less likely to have insurance compared with the white study population [19,20-23]. In our study, black patients (62.5\%) were reported to be from low-income level compared to their white counterparts (36.4\%).

A study conducted by Choi et al. showed that patients with the following characteristics, the race black, lowincome level, low educational level, advanced age, being single, smoking history, alcohol history, lower BMI, advanced clinical stage, and treated with chemotherapy were associated with poor prognosis $[24,25]$. In our study, the results observed for OS univariate analysis by Cox regression showed that having an overweight BMI, alcohol history, p16 negative status and BOT tumor subsite were associated with poor prognosis. However, in the multivariate model, we found that the BMI is the only important prognosis factor. It's been observed in other studies that black patients were higher at risk for death due to HN cancers. In our cohort, the observed differences with no statistical significance in OS considering race/ethnicity, indicates that equal clinical care (access to care and quality of care) provided at our state academic medical center and SES could bring more equity in racial/ ethnic differences observed for oropharyngeal SCCa survival rates.

Tumors induced with HPV have different biology than tobacco and alcohol-induced tumors [26-28]. HPV/p16 is one of the risk factor for oropharyngeal SCCa, but some studies showed that p16 positive tumors present a better prognosis than tobacco and alcohol-induced oropharynx tumors [29,30]. In our cohort, we observed a trend of worse OS for p16 negative (43\%) compared to p16 positive patients (69.7\%) which is inexplicable.

In our analysis of LRC, variables like gender, and BMI showed a statistically significant difference in prognosis. We observed that female patients presented a worse prognosis when compared to male patients, the overweight BMI patients presented twice the risk of relapsing oropharyngeal SCCa and p16 negative showed $19 \%$ decreased risk of relapse compared to 16 positive patients. In the multivariate analysis, gender and BMI are independent prognosis factors for LRC.

Equal access to healthcare is crucial to reduce health disparities along with lifestyle interventions such as dietary modification, smoking cessation, alcohol cessation and increased exercise should be incorporated into treatment guidelines and considered when defining research priorities.

\section{Limitations}

The number of patients in our retrospective study is very small and the income variable in this study is at the census tract level, so there might be a possibility of SES differences at the individual level confounding the racial/ ethnic differences reported.

\section{Conclusions}

Our retrospective study shows that p16 status, tumor subsites, BMI level, and alcohol history play important role in oropharyngeal SCCa survival rate. In the demographic and clinical analysis, the variables income quartile and p16 status shown statistical significance. In the univariate analysis, when adjusted for patients characteristics (BMI and alcohol history), tumor characteristics (p16 status and tumor subsite) showed a higher risk of death from oropharyngeal SCCa for our study population. In the subsequent multivariate analysis, the risk of death from oropharyngeal SCCa was no longer statistically significant for alcohol history, tumor subsite or p16 status but still high for BMI. In this retrospective study, we did not find statistical significant poor outcomes among any specific race, indicating an equal access to healthcare in our state academic medical center. In the future, we need to aim at the individual SES rather than census tract to better understand its effect on the racial disparity. In addition, studies should investigate the mechanisms surrounding the relationships between BMI and risk for HN cancer observed in this study as well as its implications on disease management and prevention.

\section{Additional Information}

\section{Disclosures}

Human subjects: Consent was obtained or waived by all participants in this study. University of Mississippi Medical Center Institutional Review Board issued approval 2010-0252. Your Continuing Review was reviewed and approved by the Expedited Review process on 06/29/2020. You may continue this research. Animal subjects: All authors have confirmed that this study did not involve animal subjects or tissue. Conflicts of interest: In compliance with the ICMJE uniform disclosure form, all authors declare the following: Payment/services info: All authors have declared that no financial support was received from any organization for the submitted work. Financial relationships: All authors have declared that they have no financial relationships at present or within the previous three years with any organizations that might have an interest in the submitted work. Other relationships: All authors have declared that there are no 
other relationships or activities that could appear to have influenced the submitted work.

\section{References}

1. Sakr M: Tumors of the Pharynx. Head and Neck and Endocrine Surgery. Sakr M (ed): Springer, Switzerland; 2016. 215-224. 10.1007/978-3-319-27532-1

2. Mahal BA, Catalano PJ, Haddad RI, et al.: Incidence and demographic burden of HPV-associated oropharyngeal head and neck cancers in the United States. Cancer Epidemiol Biomarkers Prev. 2019, 28:1660-1667. 10.1158/1055-9965.EPI-19-0038

3. American Cancer Society. Cancer facts and figures . (2019). Accessed: February 20, 2020: https://cancerstatisticscenter.cancer.org/.

4. Argiris A, Karamouzis MV, Raben D, Ferris RL: Head and neck cancer. Lancet. 2008, 371:1695-1709. 10.1016/S0140-6736(08)60728-X

5. Osazuwa-Peters N, Massa ST, Christopher KM, Walker RJ, Varvares MA: Race and sex disparities in the long-term survival of oral and oropharyngeal cancer in the United States. J Cancer Res Clin Oncol. 2015, 142:521-528. 10.1007/s00432-015-2061-8

6. Goldenberg D, Lee J, Koch WM, Kim MM, Trink B, Sidransky D, Moon C: Habitual risk factors for head and neck cancer. Otolaryngol Head Neck Surg. 2004, 131:986-993. 10.1016/j.otohns.2004.02.035

7. Gillison ML, Zhang Q, Jordan R, et al.: Tobacco smoking and increased risk of death and progression for patients with p16-positive and p16-negative oropharyngeal cancer. J Clin Oncol. 2012, 30:2102-2111. 10.1200/JCO.2011.38.4099

8. Isayeva T, Li Y, Maswahu D, Brandwein-Gensler M: Human papillomavirus in non-oropharyngeal head and neck cancers: a systematic literature review. Head Neck Pathol. 2012, 6:104-120. 10.1007/s12105-012-03681

9. Elango KJ, Suresh A, Erode EM, et al.: Role of human papilloma virus in oral tongue squamous cell carcinoma. Asian Pac J Cancer Prev. 2011, 12:889-896.

10. Viens LJ, Henley SJ, Watson M, et al.: Human papillomavirus-associated cancers-United States, 2008-2012 . MMWR Morb Mortal Wkly Rep. 2016, 65:661-666. 10.15585/mmwr.mm6526a1

11. Goodwin WJ, Thomas GR, Parker DF, et al.: Unequal burden of head and neck cancer in the United States . Head Neck. 2008, 30:358-371. 10.1002/hed.20710

12. Peterson CE, Khosla S, Chen LF, et al.: Racial differences in head and neck squamous cell carcinomas among non-Hispanic black and white males identified through the National Cancer Database (1998-2012). J Cancer Res Clin Oncol. 2016, 142:1715- 1726. 10.1007/s00432-016-2182-8

13. Mourad M, Jetmore T, Jategaonkar AA, Moubayed S, Moshier E, Urken ML: Epidemiological trends of head and neck cancer in the United States: a SEER population study. J Oral Maxi Surg. 2017, 75:2562-2572. 10.1016/j.joms.2017.05.008

14. Marur S, Forastiere AA: Head and neck cancer: changing epidemiology, diagnosis, and treatment. Mayo Clin Proc. 2008, 83:489-501. 10.4065/83.4.489

15. Bhandari RP, Duggar WN, Yang C, et al.: A sustainable model for peer review and utility of at-aglanceanalysis of dose-volume histogram in radiation oncology. J Am Coll Radiol. 2018, 15:310-312. 10.1016/j.jacr.2017.09.015

16. Reder H, Wagner S, Garmerdinger U, et al.: Genetic alterations in human papillomavirus-associated oropharyngeal squamous cell carcinoma of patients with treatment failure. Oral Oncol. 2019, 93:59-65. 10.1016/j.oraloncology.2019.04.013

17. Cathy N, Marrisa M, Laia A, et al.: HPV DNA, E6/E7 mRNA, and p16INK4a detection in head and neck cancers: a systematic review and meta-analysis. Lancet. 2014, 15:1319-1331. 10.1016/S1470-2045(14)70471-

18. Morse DE, Kerr AR: Disparities in oral and pharyngeal cancer incidence, mortality and survival among black and white Americans. J Am Dental Assoc. 2006, 137:203-212. 10.14219/jada.archive.2006.0146

19. Zakeri K, MacEwan I, Vazirnia A, et al.: Race and competing mortality in advanced head and neck cancer . Oral Oncol. 2014, 50:40-44. 10.1016/j.oraloncology.2013.09.012

20. Naghavi AO, Echevarria ML, Strom TJ, et al.: Treatment delays, race, and outcomes in head and neck cancer . Cancer Epidemiol. 2016, 45:18-25. 10.1016/j.canep.2016.09.005

21. Megwalu UC: Impact of county-level socioeconomic status on oropharyngeal cancer survival in the United States. Otolaryngol Head Neck Surg. 2017, 156:665-670. 10.1177/0194599817691462

22. Molina MA, Cheung MC, Perez EA, et al.: African American and poor patients have a dramatically worse prognosis for head and neck cancer: an examination of 20,915 patients. Cancer. 2008, 113:2797-2806. 10.1002/cncr.23889

23. Subramanian S, Chen A: Treatment patterns and survival among low-income Medicaid patients with head and neck cancer. JAMA Otolaryngol Head Neck Surg. 2013, 139:489-495. 10.1001/jamaoto.2013.2549

24. Choi SH, Terrell JE, Fowler KE, et al.: Socioeconomic and other demographic disparities predicting survival among head and neck cancer patients. PLoS One. 2016, 11:e0149886. 10.1371/journal.pone.0149886

25. Aizer AA, Chen MH, McCarthy EP, et al.: Marital status and survival in patients with cancer . J Clin Oncol. 2013, 31:3869-3876. 10.1200/JCO.2013.49.6489

26. Pirisi L, Tomar S, Glover SH: Racial disparities in Oropharyngeal Cancer. Stack M (ed): Springer, Cham; 2015. 10.1007/978-3-319-21100-8 3

27. Chakravarthy A, Henderson S, Thirdborough SM, et al.: Human papillomavirus drives tumor development throughout the head and neck: improved prognosis is associated with an immune response largely restricted to the oropharynx. J Clin Oncol. 2016, 34:4132-4141. 10.1200/JCO.2016.68.2955

28. World Health Organization (WHO). Social determinants of health. (2019). Accessed: February 18, 2020: https://www.who.int/social_determinants/en/.

29. Wang MB, Liu IY, Gornbein JA, Nguyen CT: HPV-positive oropharyngeal carcinoma: a systematic review of treatment and prognosis. Otolaryngol Head Neck Surg. 2015, 153:758-769. 10.1177/0194599815592157

30. Ragin CC, Langevin SM, Marzouk M, Grandis J, Taioli E: Determinants of head and neck cancer survival by 


\section{Cureus}

race. Head Neck. 2011, 33:1092-1098. 10.1002/hed.21584 